Esta revista forma parte del acervo de la Biblioteca Jurídica Virtual del Instituto de Investigaciones Jurídicas de la UNAM

\title{
LA AUDITORÍA SUPERIOR DE LA FEDERACIÓN Y LA CONFORMACIÓN DEL SISTEMA NACIONAL ANTICORRUPCIÓN
}

\author{
THE SUPERIOR AUDIT OF THE FEDERATION \\ AND THE CREATION OF THE NATIONAL \\ ANTICORRUPTION SYSTEM
}

\section{Miguel Angel GutiÉRrez SALAZAR*}

RESUMEN: El presente artículo tiene como objetivo reflexionar en torno a la creciente importancia que ha tomado la labor de fiscalización realizada por la Auditoría Superior de la Federación (ASF) en México. El autor expone una serie de retos que habrá de enfrentar la ASF en el contexto del vigente Sistema Nacional Anticorrupción (SNA). En el trabajo se revisa la composición y forma de funcionamiento del SNA, aludiendo al papel que habrá de desempeñar la ASF para erigirse en eje rector sustantivo. El autor ofrece una propuesta de consolidación y evolución del SNA hacia un pleno Sistema Nacional de Rendición de Cuentas. Además, el autor expone el modelo de fiscalización alemán como ejemplo de una entidad fiscalizadora de calidad y, finalmente, concluye con una serie de propuestas que tienen como finalidad fortalecer a la ASF en su desempeño como pilar sustantivo de la rendición de cuentas y el combate a la corrupción en México.

Palabras clave: Fiscalización, combate a la corrupción, transparencia, responsabilidades, rendición de cuentas.
ABSTRACT: This article aims to reflect on the growing importance that has taken control efforts made by the Superior Audit of the Federation $(A S F)$ in Mexico. The author presents a number of challenges to be faced by the ASF in the context of the current National Anti-Corruption System (SNA). This work review the composition and method of operation of the SNA, alluding to the role to be played by the ASF to establish itself as substantive rector axis. The author offers a proposal for consolidation and development of SNA towards full National Accountability System. In addition, the author presents the model of German control as an example of quality watchdog and finally, concludes with a series of proposals that aim to strengthen the ASF in its role as substantive pillar of accountability and combating corruption in Mexico.

Key words: Oversight, anti-corruption, transparency, public responsability, accountability.

* Doctor en Derecho por el Instituto de Investigaciones Jurídicas de la Universidad Nacional Autónoma de México; maestro en Derecho Constitucional y Administrativo por la Universidad Veracruzana; servidor público adscrito a la Contraloría Interna del Tribunal Electoral del Poder Judicial de la Federación. 
Esta revista forma parte del acervo de la Biblioteca Jurídica Virtual del Instituto de Investigaciones Jurídicas de la UNAM www.juridicas.unam.mx https://biblio.juridicas.unam.mx/bjv

https://revistas.juridicas.unam.mx

DOI: http://dx.doi.org/10.22201/ijj.24484881e.2017.37.11453

SUMARIO: I. Introducción. II. Reflexiones finales. III. Bibliografia.

\section{INTRODUCCIÓN}

A lo largo de los años, la Auditoría Superior de la Federación (en adelante ASF) ha tenido un papel importante en la construcción, desarrollo y perfeccionamiento de la fiscalización de los recursos públicos federales en nuestro país. Con el paso del tiempo, la labor y los esfuerzos de la ASF le han valido el reconocimiento de ser una de las instituciones más efectivas del Estado mexicano por sus resultados transparentes, objetivos, de calidad y cada vez más cercanos y comprensibles para la sociedad mexicana. ${ }^{1}$

Producto de una serie de significativas reformas constitucionales y legales, el ejercicio de la acción fiscalizadora de la ASF se ha visto robustecido, ${ }^{2}$ a la vez que se han diversificado sus tareas, abarcando aspectos ya no sólo de vigilancia y supervisión del empleo adecuado de los recursos públicos federales, sino también correspondientes a la consolidación de mecanismos de integridad en el servicio público y el combate a la corrupción.

Es precisamente en el tema del combate a la corrupción que las funciones de la ASF han alcanzado un redimensionamiento en nuestro país tras la aprobación constitucional, en mayo de 2015, del Sistema Nacional Anticorrupción (en adelante SNA).

El SNA, como será explicado más adelante, tiene como objetivos esenciales la prevención, detección y combate a la corrupción, para lo cual requiere de la suma de esfuerzos ordenados entre las distintas instituciones que participan en las tareas de transparencia, fiscalización y sanción de delitos y conductas corruptas.

1 Sandoval, Irma Eréndira, "Nuevos retos para la Auditoría Superior de la Federación”, en Ackerman, John M. y Astudillo, César (coords.), La autonomía constitucional de la Auditoría Superior de la Federación, México, UNAM, Instituto de Investigaciones Jurídicas, 2009, p. 243; Merino, Mauricio, Informe sobre la evolución y el desempeño de la Auditoría Superior de la Federación, México, Cámara de Diputados, CIDE, 2009, pp. 52-56.

2 Auditoría Superior de la Federación, 180 años de rendición de cuentas y fiscalización en México, eventos conmemorativos-memoria, México, Cámara de Diputados, Auditoría Superior de la Federación, 2004, passim; Andrade Martínez, Víctor Manuel, Evolución del marco jurídico de la fiscalización superior en México, México, Auditoría Superior de la Federación, pp. 64-72. 
Esta revista forma parte del acervo de la Biblioteca Jurídica Virtual del Instituto de Investigaciones Jurídicas de la UNAM

Es por ello que - en nuestra opinión - al ser integrante de dos importantes sistemas (Sistema Nacional de Transparencia, Acceso a la Información Pública y Protección de Datos Personales y del Sistema Nacional de Fiscalización), la ASF se constituye como el referente idóneo y pilar sustantivo del SNA.

En ese contexto, el propósito de estas líneas es reflexionar en torno a los principales retos que la ASF habrá de hacer frente para la consecución de sus metas institucionales y los objetivos de los respectivos sistemas a los que pertenece. Partimos de considerar que la ASF es (dada su experiencia en fiscalización y sus resultados) un eje central sobre el que puede edificarse sólidamente el SNA, bajo las directrices del Comité de Participación Ciudadana que lo preside.

Nuestro trabajo se estructurará a partir de los rubros temáticos siguientes:

1. Características del Sistema Nacional Anticorrupción y retos de la Auditoría Superior de la Federación. Expondremos los objetivos que se persiguen tras la aprobación constitucional del SNA, las entidades que lo habrán de conformar, sus atribuciones y los retos que de él derivan y que deberá hacer frente la ASF para alcanzar exitosamente las metas particulares y colectivas.

2. El papel de la ASF en la construcción de un Sistema Nacional de Rendición de Cuentas. Tomando como base el modelo analítico de rendición de cuentas, creado por el politólogo Andreas Schedler, identificaremos los subsistemas que componen el SNA y presentaremos una propuesta de los subsistemas que deben agregarse (de responsabilidades y participación, y contraloría social) para trascender hacia un Sistema Nacional de Rendición de Cuentas, en el que las funciones de fiscalización de la ASF sean el hilo conductor que permita dar valor a la transparencia gubernamental y eficacia al régimen de responsabilidades para el castigo de las conductas corruptas.

3. El modelo alemán de fiscalización superior y su vinculación con las instituciones de rendición de cuentas y el combate a la corrupción. Sabedores de la importancia de los análisis comparados en materia de rendición de cuentas, conoceremos el modelo alemán de fiscalización superior y su desempeño en el combate a la corrupción, el cual — desde nuestra óptica - podría ser estudiado por la ASF para la mejora sustantiva de sus procesos y funciones. 
Esta revista forma parte del acervo de la Biblioteca Jurídica Virtual del Instituto de Investigaciones Jurídicas de la UNAM www.juridicas.unam.mx https://biblio.juridicas.unam.mx/bjv

https://revistas.juridicas.unam.mx

DOI: http://dx.doi.org/10.22201/ijj.24484881e.2017.37.11453

4. Reflexiones finales. En la parte conclusiva del presente estudio se formulan algunas propuestas que tienen por objeto robustecer el papel fiscalizador de la ASF dentro del SNA, como eje rector de la eficacia gubernamental y promotor de la prevención, detección y exigencia de responsabilidades por los actos de corrupción en nuestro país.

\section{Características del Sistema Nacional Anticorrupción y retos de la Auditoría Superior de la Federación}

El 27 de mayo de 2015 fue promulgada una de las reformas constitucionales de mayor relevancia para el combate a la corrupción y la exigencia de las responsabilidades de los servidores públicos en México. Con ella se dio origen al SNA, definido en la Constitución Política de los Estados Unidos Mexicanos como: "La instancia de coordinación entre las autoridades de todos los órdenes de gobierno competentes en la prevención, detección y sanción de responsabilidades administrativas y hechos de corrupción, así como en la fiscalización y control de recursos públicos". ${ }^{3}$

En palabras del auditor superior de la Federación, el SNA busca articular en una estrategia coherente a las instituciones competentes en este tema, sean judiciales, administrativas o de fiscalización, con el fin de cerrar los espacios a riesgos reales o potenciales para la comisión de irregularidades. ${ }^{4}$

Uno de los principales propósitos y/o alcances del SNA es el de paliar los efectos negativos generados por la corrupción, la cual socava la estructura social, el principio de mayoría y las bases mismas de la democracia ${ }^{5}$ además de que corroe los valores que los colectivos humanos construyen a lo largo de la historia para alcanzar una mejor convivencia social; desarticula el tejido social y niega el valor de la ley, instaurando códigos de comportamiento extralegales basados en un conjunto preciso de antivalores. ${ }^{6}$

3 Artículo 113 de la Constitución Política de los Estados Unidos Mexicanos.

4 Portal, Juan Manuel, "Cambiemos y mejoremos todos, red por la rendición de cuentas", disponible en: http://rendiciondecuentas.org.mx/cambiemos-y-mejoremos-todos/ (última fecha de consulta: 29 de marzo de 2017).

5 Malem Seña, Jorge, F., "La corrupción política”, Jurídica, Anuario del Departamento de Derecho de la Universidad Iberoamericana, México, núm. 341, 2001, p. 586.

6 Soberanes Fernández, José Luis, "La lucha contra la corrupción no está perdida", en González Llaca, Edmundo, Corrupción, patología colectiva, México, INAP, 2005, 
Esta revista forma parte del acervo de la Biblioteca Jurídica Virtual del Instituto de Investigaciones Jurídicas de la UNAM www.juridicas.unam.mx https://biblio.juridicas.unam.mx/bjv https://revistas.juridicas.unam.mx

DOI: http://dx.doi.org/10.22201/iij.24484881e.2017.37.11453

Para nadie es ajeno que los niveles de percepción de la corrupción en México son alarmantes y — de acuerdo con Casar- los pocos o muchos intentos para reducirlos han sido un fracaso, ${ }^{7}$ razón por la cual el diseño y funcionamiento adecuado del SNA tiene mayor importancia.

Tan sólo como botón de muestra de los altos índices de percepción de la corrupción en México baste señalar el Índice de Percepción de la Corrupción (IPC) 2016, elaborado por Transparencia Internacional, según el cual México es visto como un país muy corrupto; la calificación obtenida en ese año es de treinta puntos (de cien posibles), y ocupa el lugar 123 de 176 países estudiados y con relación a los países de nuestro continente se encuentra ubicado por debajo de la mayoría.
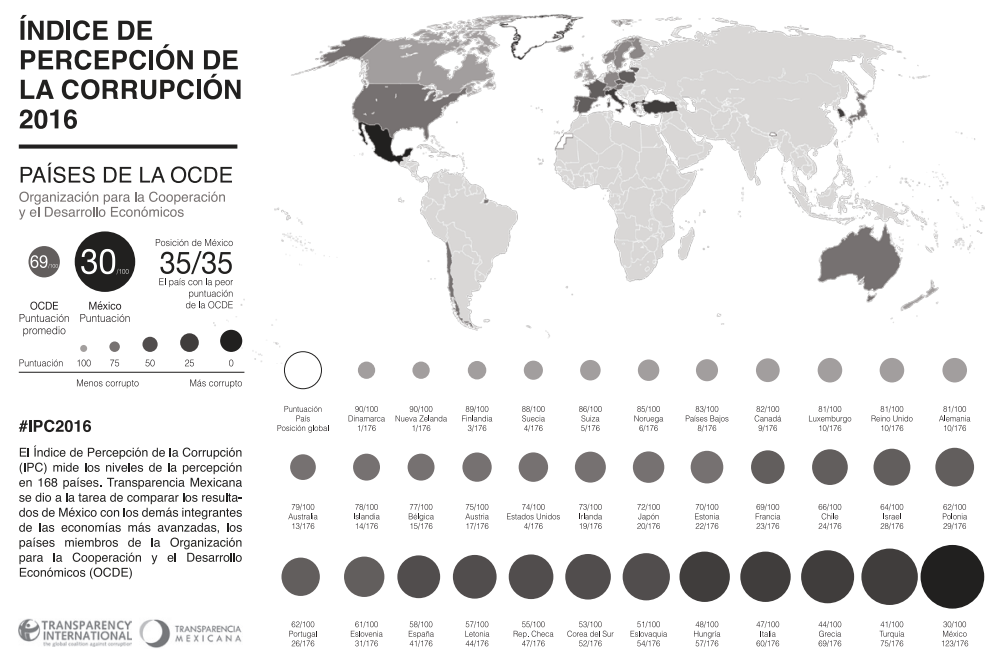

FUENTE: Transparencia Internacional. Índice de Percepción de la Corrupción (IPC) 2016-Países de la OCDE.

Frente a datos tan contundentes, se comprende que la creación del SNA responde a la intención de implementar un mecanismo que desincentive y sancione los espacios y conductas que atentan contra los valores del servicio público y merman la eficacia institucional.

disponible en: http://biblio.juridicas.unam.mx/libros/libro.htm?l=1680 (última fecha de consulta: 29 de marzo de 2017).

7 Casar, María Amparo, México: anatomía de la corrupción, México, IMCO, CIDE, 2015, p. 12. 
Esta revista forma parte del acervo de la Biblioteca Jurídica Virtual del Instituto de Investigaciones Jurídicas de la UNAM www.juridicas.unam.mx https://biblio.juridicas.unam.mx/bjv

https://revistas.juridicas.unam.mx

DOl: http://dx.doi.org/10.22201/iij.24484881e.2017.37.11453

El diseño del SNA — tal y como se determina en la Constitución- auspicia la colaboración de las principales instituciones que pueden incidir en la prevención, detección y sanción de actos corruptos. El artículo 113 constitucional dispone que el SNA:

Contará con un Comité Coordinador que estará integrado por los titulares de la Auditoría Superior de la Federación; de la Fiscalía Especializada en Combate a la Corrupción; de la secretaría del Ejecutivo Federal responsable del control interno; por el presidente del Tribunal Federal de Justicia Administrativa; el presidente del organismo garante que establece el artículo 6o. de esta Constitución; así como por un representante del Consejo de la Judicatura Federal y otro del Comité de Participación Ciudadana.

\section{ESTRUCTURA DEL COMITÉ COORDINADOR DEL SNA}

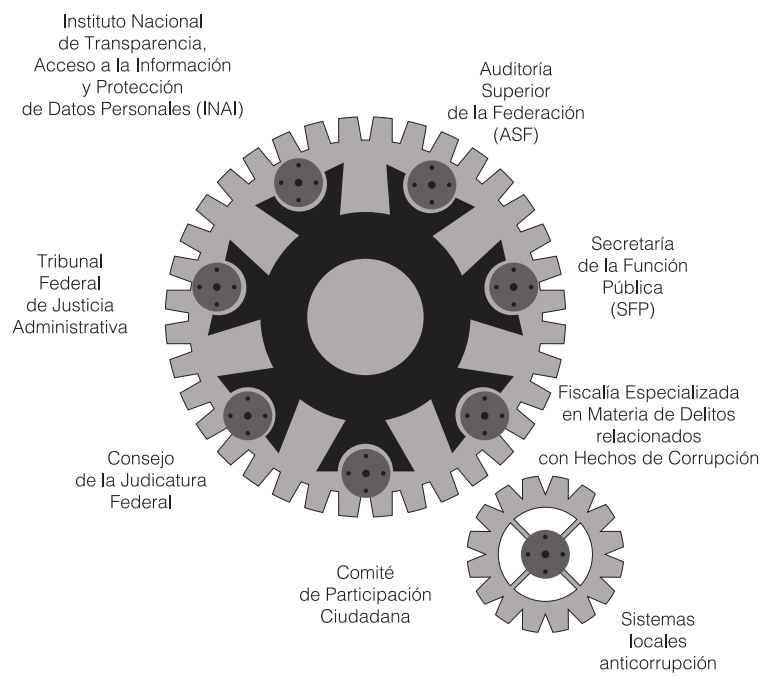

(32)

FUente: Informe General de la Cuenta Pública 2014-ASF.

Es decir, el Comité coordinador es pieza fundamental del SNA, se integra por una pluralidad de instituciones especializadas en las más diversas materias relacionadas con la rendición de cuentas: ${ }^{8}$

8 Conforme a estas reflexiones, el entendimiento de la concepción del SNA se aproxima a la definición de "sistema" previsto por la Real Academia Española, la cual dispo- 
Esta revista forma parte del acervo de la Biblioteca Jurídica Virtual del Instituto de Investigaciones Jurídicas de la UNAM

a) La Auditoría Superior de la Federación encargada de la fiscalización de los recursos públicos federales (cuya integración, organización y funcionamiento encuentra sustento normativo en el artículo 79 de la Constitución federal, así como en la Ley de Fiscalización y Rendición de Cuentas de la Federación publicada en el Diario Oficial de la Federación el 18 de julio de 2016). ${ }^{9}$

b) La Fiscalía Especializada en Combate a la Corrupción, competente para conocer las investigaciones y promover las acciones penales en contra de quienes incurran en actos de corrupción.

c) La Secretaría de la Función Pública, a cargo de velar por el correcto funcionamiento de los sistemas de control interno y el óptimo desempeño de las contralorías adscritas a las dependencias públicas federales.

d) El Tribunal Federal de Justicia Administrativa con atribuciones para juzgar los actos de corrupción y las faltas administrativas graves.

e) El Instituto Nacional de Transparencia, Acceso a la Información y Protección de Datos Personales, garante del derecho ciudadano del acceso a la información pública gubernamental y de la privacidad de los datos personales. ${ }^{10}$

f) El Consejo de la Judicatura Federal, institución que rige la administración, vigilancia, disciplina y carrera del Poder Judicial de la Federación. ${ }^{11}$

g) El Comité de Participación Ciudadana, integrado por cinco expertos en transparencia, rendición de cuentas o combate a la corrup-

ne: Sistema: 1. Conjunto de reglas o principios sobre una materia racionalmente enlazados entre sí; 2. Conjunto de cosas que relacionadas entre sí ordenadamente contribuyen a determinado objetivo. Cfr. Diccionario de la Lengua Española, disponible en: http://dle. rae.es/? id=Y2AFX5s (última fecha de consulta: 29 de marzo de 2017).

9 Más información en la página web de la ASF: http://www.asf.gob.mx/ (última fecha de consulta: 29 de marzo de 2017). Para conocer acerca del proceso de fiscalización superior de la cuenta pública, se sugiere consultar los artículos 74, fracción VI y 79 de la Constitución federal, así como 13 a 46 de la Ley de Fiscalización y Rendición de Cuentas de la Federación. Adicionalmente, véase Romero Gudiño, Alejandro, Génesis, evolución y retos de la fiscalización superior en México, México, Cámara de Diputados, LXIII Legislatura, Centro de Estudios de Derecho e Investigaciones Parlamentarias, 2016, passim.

10 A mayor abundamiento, véase la página del INAI: http://inicio.inai.org. $m x / S i t e P a-$ ges/misionViosionObjetivos.aspx (última fecha de consulta: 29 de marzo de 2017).

11 Página web del Consejo de la Judicatura Federal: http://www.cjf.gob.mx/misionVision.htm (última fecha de consulta: 29 de marzo de 2017). 
Esta revista forma parte del acervo de la Biblioteca Jurídica Virtual del Instituto de Investigaciones Jurídicas de la UNAM

ción. ${ }^{12}$ El representante de este Comité es quien preside al Comité Coordinador del SNA, conforme a la Ley General del Sistema Nacional Anticorrupción, de ahí su importancia. ${ }^{13}$

Al ser un elemento central del SNA, al Comité coordinador le compete el diseño y promoción de políticas en materia de fiscalización y control de recursos públicos, de prevención, control y disuasión de faltas administrativas y hechos de corrupción. Asimismo, tiene competencia para determinar los mecanismos de suministro, intercambio, sistematización y actualización de información sobre estas materias y para establecer bases y principios para la efectiva coordinación de las autoridades de los órdenes de gobierno en materia de fiscalización y control de los recursos públicos.

Al Comité coordinador del SNA corresponde también la elaboración de un informe anual que contenga los avances y resultados del ejercicio de sus funciones y de la aplicación de políticas y programas en la materia, así como la importante función de emitir recomendaciones no vinculantes a las autoridades, con el objeto de que adopten medidas dirigidas al fortalecimiento institucional, para la prevención de faltas administrativas y hechos de corrupción y al mejoramiento de su desempeño y del control interno.

A partir de esas premisas y con la finalidad de que los esfuerzos en el combate a la corrupción sean homogéneos en todo el país, por mandato constitucional las entidades federativas están llamadas a establecer sistemas locales anticorrupción, bajo los mecanismos de coordinación que establezca el Comité coordinador del SNA.

Lo anterior obedece, como Eduardo Bohórquez lo ha expresado, a la necesidad de que las políticas anticorrupción se implementen en todos los poderes y en los tres órdenes de gobierno en el país, ${ }^{14}$ de ahí la importancia

12 Actualmente integrado por: Mariclaire Acosta Urquidi, Alfonso Hernández Valdez, José Octavio López Presa, Luis Manuel Pérez de Acha y Jacqueline Peschard Mariscal, esta última es quien lo preside, al igual que al Comité Coordinador del SNA. A mayor abundamiento y para conocer una breve semblanza de los integrantes del Comité de Participación Ciudadana, se sugiere la página de internet: http://www.animalpolitico.com/2017/01/ designan-ciudadanos-comite-anticorrupcion/ (consultado: 29 de marzo de 2017).

13 La Ley General del Sistema Nacional Anticorrupción, la Ley General de Responsabilidades Administrativas y la Ley Orgánica del Tribunal Federal de Justicia Administrativa, fueron publicadas en el Diario Oficial de la Federación del 18 de julio de 2016.

14 Bohórquez, Eduardo, Conflicto de interés y Sistema Nacional Anticorrupción, disponible en: http://www.eluniversalmas.com.mx/editoriales/2015/02/74665.php (última fecha de consulta: 29 de marzo de 2017). 
Esta revista forma parte del acervo de la Biblioteca Jurídica Virtual del Instituto de Investigaciones Jurídicas de la UNAM

de que el Comité coordinador del SNA centre sus esfuerzos en una coordinación eficaz con los sistemas locales anticorrupción.

Pero la reforma constitucional anticorrupción que dio vida al SNA no se limitó a las modificaciones antes expuestas, sino que consideró otros elementos indispensables para el combate a la corrupción, entre los que podemos destacar: $a$ ) la exigencia de que los servidores públicos presenten una declaración de intereses, además de la patrimonial y la fiscal; ${ }^{15} b$ ) la creación del Tribunal Federal de Justicia Administrativa como órgano jurisdiccional que sancionará a los servidores públicos y particulares por actos de corrupción; c) el incremento de la prescripción por delitos de corrupción a siete años; $d$ ) la designación de los titulares de los órganos de control interno de los organismos autónomos por parte de la Cámara de Diputados, y e) la ratificación del nombramiento del secretario de la Función Pública por parte del Senado de la República. ${ }^{16}$

En el ámbito de la ASF, la reforma anticorrupción de 2015 amplió sus facultades para realizar auditorías en curso y de años anteriores (con lo cual se eliminaron los principios de anualidad y posterioridad a que estaba sujeta); así como para fiscalizar los recursos federales destinados a estados y municipios, los ejercidos por fideicomisos, fondos y mandatos, públicos y privados (artículo 79 constitucional), por lo que los trabajos de vigilancia y fiscalización de la ASF se vieron maximizados en gran manera.

Ante el contexto descrito, cabe preguntarnos cuáles son los desafíos que con motivo de la reforma anticorrupción 2015 enfrenta la ASF. En ese sentido, podemos identificar al menos tres desafíos importantes:

1. El primer desafío consiste en la elaboración de políticas de fiscalización claras, homogéneas y congruentes, no sólo para que

15 Sobre este tema, debe señalarse la importante iniciativa denominada "tres de tres", impulsada por el Instituto Mexicano para la Competitividad (IMCO) y Transparencia Mexicana (TM), en donde a través de la plataforma digital http://tresdetres. $m x /$ se dan a conocer las declaraciones patrimonial, fiscal y de intereses de los servidores públicos a nivel federal, estatal y municipal que así lo deseen. En esa base de datos se pueden ver publicadas, a manera de instrumento parcial de rendición de cuentas, sujeto a comprobación, los datos concernientes al manejo del patrimonio, la responsabilidad fiscal y legal de los servidores públicos de los tres órdenes de gobierno. Iniciativas como estas deben propiciarse, a fin de promover la honestidad y el sentido de responsabilidad en la función pública.

16 Artículo periodístico intitulado: "14 claves del Sistema Nacional Anticorrupción”, disponible en: http://www.cnnexpansion.com/economia/2015/02/26/12clavesdelsisteman acionalanticorrupcion (última fecha de consulta: 29 de marzo de 2017). 
Esta revista forma parte del acervo de la Biblioteca Jurídica Virtual del Instituto de Investigaciones Jurídicas de la UNAM

merezcan el soporte y apoyo en su aprobación por parte de los integrantes del SNA, sino sobre todo para que sean asequibles, comprensibles y fácilmente aplicables por los entes auditados de los tres órdenes de gobierno.

Como ha señalado Mauricio Merino, una política pública (en este caso de fiscalización) constituye la intervención deliberada para corregir o modificar una situación social o económica que ha sido reconocida como problema público, ${ }^{17}$ de ahí que, en el caso de las políticas orientadas a la vigilancia y fiscalización de los recursos públicos federales, la ASF — como institución especializada — deba acompañar el complejo proceso que normalmente caracteriza a una política pública, ${ }^{18}$ procurando que las políticas de fiscalización tiendan en todo momento hacia cometidos éticos y la eficacia institucional.

2. El segundo desafío radica en la interacción y coordinación efectiva entre la ASF y el resto de los integrantes del SNA, los órganos de fiscalización superior de los estados y las auditorías internas de los gobiernos estatales; es decir, implica una tarea ardua para la coordinación positiva entre distintas instituciones públicas (Secretaría de la Función Pública, Consejo de la Judicatura Federal, etcétera) en diferentes niveles de gobierno e incluso entre distintos niveles de poder.

El propio auditor superior de la Federación ha señalado que se trata de una labor compleja porque son muchos los participantes y la coordinación no es una tendencia natural en las organizaciones. ${ }^{19}$

3. El tercer desafío estriba en superar las limitadas capacidades que necesariamente la ASF — como cualquier institución - tiene para asumir las nuevas atribuciones que constitucionalmente se le han dado.

17 Merino, Mauricio, Politicas públicas. Ensayo sobre la intervención del Estado en la solución de problemas públicos, México, CIDE, 2013, p. 17.

18 Generalmente se ha identificado que el proceso de políticas públicas comprende las etapas siguientes: identificación de problemas; definición de objetivos, actores y alternativas; análisis de posibles modificaciones al marco jurídico; precisión de los costos y recursos que se han de asumir; concreción de las acciones y responsables de su atención; diseño de los calendarios de seguimiento; y por último, evaluaciones de la política implementada para su perfeccionamiento. Aguilar Villanueva, Luis, El estudio de las políticas públicas, 3a. ed., México, Miguel Ángel Porrúa, 2007, passim.

19 Portal, Juan Manuel, "Relanzamiento del SNF", blog de la ASF, disponible en: http://blog-asf.gob.mx/?p=886 (última fecha de consulta: 29 de marzo de 2017). 
Esta revista forma parte del acervo de la Biblioteca Jurídica Virtual del Instituto de Investigaciones Jurídicas de la UNAM www.juridicas.unam.mx

Aquí nos parece que resultará necesario que la ASF identifique sus limitaciones en cuanto a personal y recursos, para asegurarse de que estará en óptimas condiciones de alcanzar los objetivos constitucionales, o bien promueva ante las instancias pertinentes, mayores elementos técnicos, normativos, humanos y materiales para la consecución de dichas metas.

Los primeros dos desafíos señalados quizá revistan mayor complejidad que el tercero, ya que implican el diseño de políticas y la coordinación interinstitucional, aunque, como analizaremos posteriormente, pueden y deben superarse por la ASF.

Prueba de que ello es posible son los trabajos que la ASF ha venido haciendo en el marco del Sistema Nacional de Fiscalización para homologar parámetros y criterios de fiscalización, así como el acercamiento (mediante una comunicación abierta y directa) con los integrantes de las entidades federativas que son parte del propio Sistema.

\section{NuEVOS DESAFÍOS PARA LA ASF}

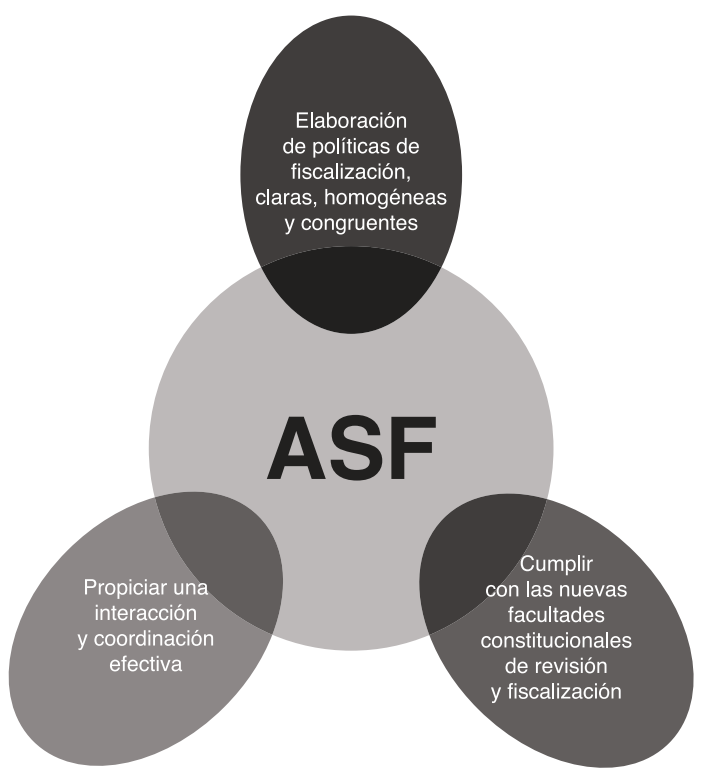

FUENTE: Elaboración propia. 
Esta revista forma parte del acervo de la Biblioteca Jurídica Virtual del Instituto de Investigaciones Jurídicas de la UNAM www.juridicas.unam.mx https://biblio.juridicas.unam.mx/bjv

https://revistas.juridicas.unam.mx

DOI: http://dx.doi.org/10.22201/iij.24484881e.2017.37.11453

Como veremos en el apartado subsecuente, los nuevos desafíos que afrontará la ASF deben comprenderse como parte de un régimen de rendición de cuentas que opere bajo una visión de sistema integral y coherente, es decir, excede el solo combate a la corrupción y busca sumar esfuerzos y acciones para la mejora administrativa y la eficacia de las instituciones públicas en México.

\section{El papel de la ASF en la construcción de un Sistema Nacional de Rendición de Cuentas ${ }^{20}$}

El politólogo Andreas Schedler es autor de dos obras esenciales para comprender el significado de la rendición de cuentas: Conceptualizing accountability y ¿Qué es la rendición de cuentas? ${ }^{21}$

Según el modelo teórico propuesto por Schedler, la rendición de cuentas involucra la obligación de las autoridades de informar y justificar sus actos y determinaciones ante la sociedad, con la posibilidad de sancionarlas cuando su actividad sea contraria a la legalidad. ${ }^{22}$

Para Schedler, la rendición de cuentas comprende, al menos, tres elementos que tienen como propósito prevenir, subsanar y, en su caso, castigar el abuso del poder; estos elementos son: ${ }^{23}$

20 El modelo de Sistema Nacional de Rendición de Cuentas que se propone abreva de las ideas planteadas por el doctor Mauricio Merino Huerta. El doctor Merino ha señalado que entiende a la rendición de cuentas como una cadena integrada por un conjunto de componentes: un servicio profesional de carrera, un buen sistema de archivos, una buena asignación de los presupuestos, el acceso pleno a la información pública (gobierno abierto), un buen sistema contable, sistemas abiertos de compras públicas, la mejor fiscalización posible, monitoreo y evaluación de políticas públicas y supervisión ciudadana". Merino, Mauricio et al., "Por un sistema de rendición de cuentas", en Peschard, Jacqueline (coord.), Hacia el Sistema Nacional de Transparencia, México, UNAM, Instituto de Investigaciones Jurídicas, Seminario Universitario de Transparencia, 2016, p. 99; Merino, Mauricio et al. (coords.), La estructura de la rendición de cuentas en México, México, UNAM, Instituto de Investigaciones Jurídicas, CIDE, 2010, passim.

21 Schedler, Andreas, "Conceptualizing accountability", en Schedler, Andreas et al. (eds.), The Selfrestraning State: Power and Accountability in New Democracies, Boulder, Lynne Rienner, 1999; Schedler, Andreas, ¿Qué es la rendición de cuentas?, 4a. ed., México, IFAI, 2007, Cuadernos de transparencia núm. 3.

22 Ibidem, p. 12.

23 Schedler, Andreas, "Conceptualizing accountability..., cit., p. 14. 
Esta revista forma parte del acervo de la Biblioteca Jurídica Virtual del Instituto de Investigaciones Jurídicas de la UNAM

a) La información de las actividades gubernamentales;

b) La justificación de las mismas, y

c) El castigo de los responsables en caso de ilegalidad.

La información y justificación de las actividades de gobierno se materializan a través de la obligación de las autoridades de proporcionar y divulgar los datos vinculados con sus decisiones y una explicación de los mismos, en tanto que el castigo significa la posibilidad de demandar legalmente el apego de las autoridades a la normatividad legal vigente, incluso sancionando las conductas impropias de los servidores públicos. ${ }^{24}$

Con base en dicho modelo teórico, creemos que el SNA reúne elementos, que armonizados y fortalecidos con la participación ciudadana y el perfeccionamiento de un régimen de responsabilidades, inciden en el combate a la corrupción y propician un entorno de integridad bajo el cual puedan las instituciones públicas prestar servicios de calidad.

Desde nuestra perspectiva - y siguiendo el modelo de Schedler-, el diseño actual del SNA se integra por dos subsistemas:

1. Subsistema Nacional de Transparencia. Instancia de coordinación y deliberación, que tiene como objetivo la organización de los esfuerzos de cooperación, colaboración, promoción, difusión y articulación permanente en materia de transparencia, acceso a la información y protección de datos. ${ }^{25}$

2. Subsistema Nacional de Fiscalización. Conjunto de principios y actividades estructurados y vinculados entre sí, que buscan establecer un ambiente de coordinación efectiva entre todos los órganos gubernamentales de fiscalización en el país, con el fin de trabajar, en lo posible, bajo una misma visión profesional con similares estándares, valores éticos y capacidades técnicas, a efecto de proporcionar certidumbre a los entes auditados y garantizar a la ciudadanía que la revisión al uso de los recursos públicos se hará de una manera más ordenada, sistemática e integral. ${ }^{26}$

24 Schedler, Andreas, ¿Qué es la rendición..., cit., p. 16.

25 Página web del Sistema Nacional de Transparencia: http://www.snt.org.mx/(última fecha de consulta: 29 de marzo de 2017).

26 Página web del Sistema Nacional de Fiscalización: http://www.snf.org.mx/defi nici\%C3\%B3n.aspx (última fecha de consulta: 29 de marzo de 2017). 
Esta revista forma parte del acervo de la Biblioteca Jurídica Virtual del Instituto de Investigaciones Jurídicas de la UNAM www.juridicas.unam.mx https://biblio.juridicas.unam.mx/bjv

https://revistas.juridicas.unam.mx

DOI: http://dx.doi.org/10.22201/ijj.24484881e.2017.37.11453

Dichos subsistemas dan forma al vigente SNA: el Subsistema Nacional de Transparencia (de reciente creación) tiene como máxima autoridad al Consejo Nacional de Transparencia, integrado por el INAI, sus similares de las entidades federativas, la ASF, el Archivo General de la Nación y el Instituto Nacional de Estadística y Geografía (INEGI).

Por su parte, el Subsistema Nacional de Fiscalización (en funcionamiento desde hace más de cinco años) es presidido por la ASF y la Secretaría de la Función Pública, integrado también por las entidades de fiscalización superior de los estados, los miembros de la Asociación Nacional de Organismos de Fiscalización Superior y Control Gubernamental, A.C. (Asofis) y las secretarías de las contralorías de los estados, integrantes de la Comisión Permanente de Contralores de Estados-Federación (CPCE-F).

El Subsistema Nacional de Transparencia y su Consejo Nacional son fundamentales para el ejercicio del derecho de acceso a la información en nuestro país, en su seno se propiciará la armonización de la ley federal (y las leyes locales en la materia) con la Ley General en Transparencia, además de la puesta en marcha de una Plataforma Nacional de Transparencia.

En el marco de este Consejo se gestarán los programas conjuntos de promoción, vinculación, diagnóstico, investigación, difusión, capacitación y profesionalización, que servirán para preparar a los servidores públicos estatales y municipales en el cumplimiento de sus obligaciones de transparencia. $^{27}$

A su vez, la trascendencia del Subsistema Nacional de Fiscalización es tal que ha sido considerado como el de mayor importancia dentro del $S N A,{ }^{28}$ organizado a partir de cuatro líneas de acción: visión estratégica, normas profesionales, control interno y responsabilidades de los servidores públicos, y un plan estratégico vigente para el periodo 2013-2017 que contempla seis líneas estratégicas: ${ }^{29}$

27 Puente de la Mora, Ximena, Sistema Nacional de Transparencia, base de un México más abierto, disponible en: http://mexico.cnn.com/opinion/2015/06/23/opinion-sistema-nacional-de-transparencia-base-de-un-mexico-mas-abierto (última fecha de consulta: 29 de marzo de 2017).

28 Portal, Juan Manuel, Mensaje del Auditor Superior de la Federación con motivo del Relanzamiento del Sistema Nacional de Fiscalización, disponible en: http://www.asf. gob.mx/uploads/74_Mensajes_del_Titular/Relanzamiento_del_Sistema_Nacional_de_ Fiscalizacion_22_Jul.pdf(última fecha de consulta: 29 de marzo de 2017).

29 Metas del Sistema Nacional de Fiscalización, disponibles en: http://www.snf.org. mx/metas.aspx_(última fecha de consulta: 29 de marzo de 2017). 
Esta revista forma parte del acervo de la Biblioteca Jurídica Virtual del Instituto de Investigaciones Jurídicas de la UNAM

1. Normas profesionales comunes a nivel nacional.

2. Creación de capacidades.

3. Intercambio de información y trabajo conjunto.

4. Mejoras en el marco legal y operativo vinculado con la fiscalización.

5. Mayor impacto de la labor de los órganos de auditoría gubernamental en el combate a la corrupción.

6. Fortalecimiento del papel de la fiscalización en la promoción, determinación y fincamiento de responsabilidades de servidores públicos.

El Subsistema Nacional de Fiscalización ha sido impulsado por la ASF desde 2010, por lo que las líneas estratégicas anteriormente definidas (incluido el combate a la corrupción) vienen siendo materia de trabajo desde varios años antes al surgimiento del actual SNA, lo que convierte al Subsistema de Fiscalización y a la ASF en pilares de la rendición de cuentas en México $\mathrm{y}$, sin duda, pueden facilitar el alcance de los propósitos anticorrupción que dieron origen a la reforma constitucional de 2015.

Si han existido algunos cuestionamientos sobre los alcances de la fiscalización y se ha afirmado por especialistas en la materia que: "México carece de una cultura de rendición de cuentas y transparencia", ${ }^{30}$ lo cierto es que el Subsistema Nacional de Fiscalización cuenta con algunos logros, entre los que podemos mencionar: ${ }^{31}$

a) La concientización, a nivel nacional, de los requisitos mínimos de un trabajo de auditoría con calidad y prevalencia de los principios de independencia e integridad;

b) La creación de un marco nacional de normas profesionales de auditoría basado en los estándares definidos por la INTOSAI;

c) La instauración de una cultura de control interno en las instituciones públicas, $\mathrm{y}$

d) La promoción de modelos como el Coso (Comité de Organizaciones Patrocinadoras de la Comisión Treadway) en su última versión, entre otras.

30 Palabras de Arturo González de Aragón, exauditor superior de la Federación, Revista del Colegio de Contadores Públicos de México, disponible en: http://www.ccpm. org.mx/avisos/octubreentrevista.pdf (última fecha de consulta: 29 de marzo de 2017).

31 Auditoría Superior de la Federación, Informe general de la cuenta pública 2013, ASF, México, 2015, disponible en: http://www.asf.gob.mx/uploads/55_Informes_de_auditoria/Informe_General_CP_2013.pdf(última fecha de consulta: 29 de marzo de 2017). 
Esta revista forma parte del acervo de la Biblioteca Jurídica Virtual del Instituto de Investigaciones Jurídicas de la UNAM www.juridicas.unam.mx https://biblio.juridicas.unam.mx/bjv

https://revistas.juridicas.unam.mx

DOI: http://dx.doi.org/10.22201/ijj.24484881e.2017.37.11453

Pero la ASF no limita su participación exclusivamente al SNF, sino que - como mencionamos - también aporta una dosis importante de experiencia al Subsistema Nacional de Transparencia y a través de su colaboración busca establecer una cultura de legalidad, control y rendición de cuentas, donde cada área, e inclusive, cada integrante del aparato estatal, enfrenten un sistema definido por la fiscalización, la transparencia y la existencia de sanciones efectivas.

Ahora bien, desde nuestra perspectiva, el SNA atiende parcialmente al modelo teórico que señalamos y puede fortalecerse y trascender hacia un Sistema Nacional de Rendición de Cuentas de mayores alcances. Esto sería posible - nuevamente desde nuestro punto de vista - si los dos subsistemas que ya estudiamos se coordinaran con un Subsistema Nacional de Responsabilidades y un Subsistema Nacional de Participación y Contraloría Social.

De esta forma, el modelo teórico propuesto por Schedler vería materializados los tres elementos de la rendición de cuentas (información, justificación y castigo), y se le añadiría la participación ciudadana (societal accountability), misma que para algunos autores: "Depende de la activación de grupos ciudadanos, movimientos sociales y medios de comunicación para exponer irregularidades en el gobierno, atraer la atención pública a temas específicos, o exigir acción por parte de alguna institución". ${ }^{32}$

De lo que se trataría es de armonizar integralmente los cuatro subsistemas en un Sistema Nacional de Rendición de Cuentas que no sólo se enfoque en el combate a la corrupción, sino en la integridad de las instituciones y en la eficacia gubernamental.

De acuerdo con nuestra propuesta, el Subsistema Nacional de Responsabilidades sería un mecanismo de coordinación para exigir la responsabilidad de los servidores públicos en México, bajo los elementos que hoy tenemos dispersos pero que debidamente integrados pudieran configurar una estrategia eficaz de prevención, investigación y sanción en contra de las faltas administrativas y delitos (incluidos los actos de corrupción) derivados del ejercicio del servicio público.

En tanto que el Subsistema Nacional de Participación y Contraloría Social, al igual que el subsistema anterior, sería una instancia de coordinación que robustecería los factores (normativos, organizacionales, de procedimien-

32 Cejudo Ramírez, Guillermo Miguel, Todas las piezas en su lugar: La arquitectura institucional de la rendición de cuentas en México, México, Auditoría Superior de la Federación, 2005, p. 50. 
Esta revista forma parte del acervo de la Biblioteca Jurídica Virtual del Instituto de Investigaciones Jurídicas de la UNAM www.juridicas.unam.mx https://biblio.juridicas.unam.mx/bjv https://revistas.juridicas.unam.mx

DOI: http://dx.doi.org/10.22201/iij.24484881e.2017.37.11453

tos, etcétera) que hoy se tienen para propiciar la participación y contraloría social como una instancia decisiva en la vigilancia de los actos y decisiones de gobierno en México. Sus instrumentos serían: la transparencia y el acceso a la información; la participación en actividades de fiscalización; las denuncias en contra de los actos de los servidores públicos que atenten contra la legalidad, etcétera.

\section{SUBSISTEMAS QUE PODRÍAN INTEGRAR UN SISTEMA NACIONAL DE RENDICIÓN DE CUENTAS}

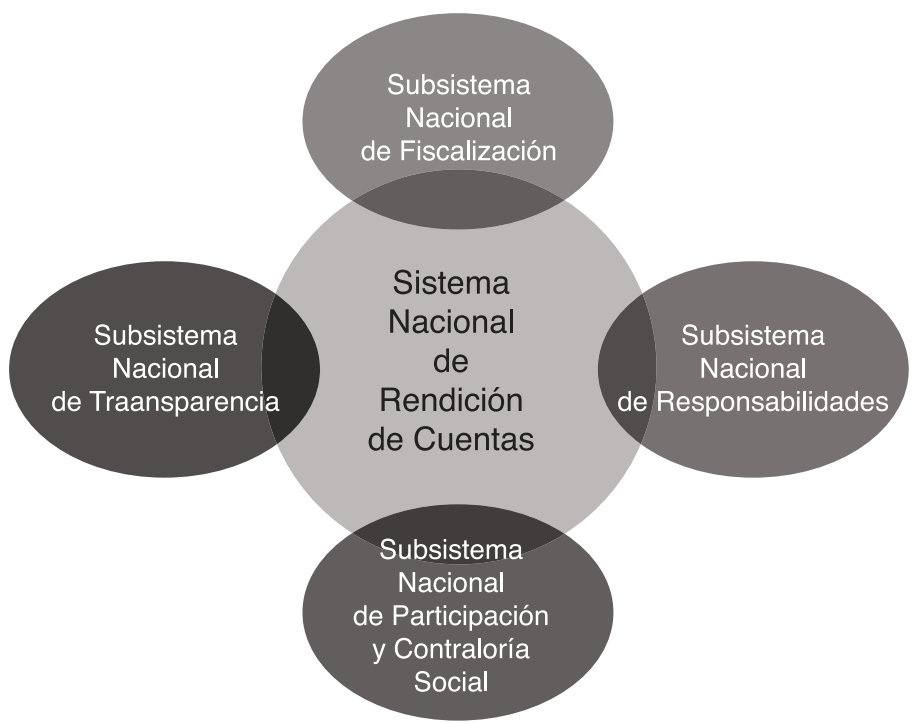

FUENTE: Elaboración propia.

Desde nuestra óptica y conforme al modelo de Sistema Nacional de Rendición de Cuentas que proponemos, la ASF junto al Comité de Participación Ciudadana, ejercería un liderazgo sustantivo en la construcción de los Subsistemas Nacionales de Responsabilidades y de Participación y Contraloría Social.

Para ello, el fortalecimiento de las atribuciones reconocidas a la ASF con motivo de la reforma constitucional anticorrupción 2015, debe ahora orientarse hacia la consolidación de ese órgano fiscalizador, con miras a robustecer su grado de autonomía y blindaje político, de manera semejante 
Esta revista forma parte del acervo de la Biblioteca Jurídica Virtual del Instituto de Investigaciones Jurídicas de la UNAM www.juridicas.unam.mx https://biblio.juridicas.unam.mx/bjv

https://revistas.juridicas.unam.mx

DOI: http://dx.doi.org/10.22201/ijj.24484881e.2017.37.11453

a lo que ocurre en el modelo fiscalizador alemán, sobre el que expondremos más adelante.

Por cuanto hace al Subsistema Nacional de Responsabilidades, ${ }^{33}$ se integraría por el conjunto de normas, instituciones, procesos, políticas públicas, criterios y acciones dirigidos a garantizar la correcta actuación de los servidores públicos en el ejercicio de sus funciones, sancionándolos en los supuestos en que exista una vulneración a las normas que rigen la función pública y estableciendo, en su caso, los medios para la recuperación económica de los daños y perjuicios causados con la conducta infractora. ${ }^{34}$

El papel de la ASF en este subsistema sería importante, dado que en ejercicio de sus funciones, ya se ha encargado de investigar aquellos hechos irregulares que pudieran derivar en una falta administrativa o un delito sancionable por las leyes vigentes, llevando a cabo las denuncias administrativas o penales pertinentes y dándole el seguimiento requerido a lo largo de los procedimientos jurídicos.

Como puede desprenderse de la plataforma web denominada Sistema Público de Consulta de Auditorías, ${ }^{35}$ de 2000 a 2015, la ASF ha presentado un total de 581 denuncias de hechos y ha ejercido la promoción de 16,565 responsabilidades administrativas sancionatorias, derivadas de 226 y 4,559 auditorías, respectivamente, lo que da cuenta de la vinculación

33 No pasa desapercibido, que con la reforma constitucional de 1982 en materia de responsabilidades se buscó la renovación moral de la sociedad y del servicio público. No obstante, los importantes cambios normativos e institucionales que implicó su implementación a nivel nacional careció de perspectiva sistemática, pericia técnica $y$, sobre todo a nivel de las entidades federativas, de efectiva voluntad política que permitiera generar un entorno sólido de probidad en la función pública y en la prestación de los servicios a la sociedad. Sobre este tema se recomienda, Kaiser, Max, El combate a la corrupción. La gran tarea pendiente en México, México, ITAM, Miguel Ángel Porrúa, 2014, pp. 63-77.

34 En este subsistema debe comprenderse la participación de las autoridades encargadas de conocer las cuatro modalidades de responsabilidad de los servidores públicos en el ámbito político, civil, penal y administrativo. Ilustra al respecto, la tesis: "RESPONSABILIDADES DE SERVIDORES PÚBLICOS. SUS MODALIDADES DE ACUERDO CON EL TÍTULO CUARTO COnstitucional". Tesis P. LX/96, Novena Época, Semanario Judicial de la Federación y su Gaceta, abril de 1996, p. 128.

Gutiérrez Salazar, Miguel Ángel, Hacia la construcción de un sistema de rendición de cuentas armónico, como mecanismo para el fortalecimiento de la eficacia institucional y el combate a la corrupción en México, México, Auditoría Superior de la Federación, Cámara de Diputados, CIDE, UNAM-ASOFIS, 2013, pp. 89 y 90.

35 Sistema Público de Consulta de Auditorías, ASF, disponible en: http://www.asfdatos.gob.mx/_última fecha de consulta: 29 de marzo de 2017). 
Esta revista forma parte del acervo de la Biblioteca Jurídica Virtual del Instituto de Investigaciones Jurídicas de la UNAM www.juridicas.unam. $m x$

de la ASF con los elementos conformadores del Subsistema Nacional de Responsabilidades (autoridades, mecanismos de denuncia, procedimientos legales, etcétera) por lo que nos lleva a pensar que la ASF necesariamente debe ser una instancia que oriente la conformación de dicho Subsistema en México.

\section{INTERACCIÓN DE LOS SUBSISTEMAS DE TRANSPARENCIA, FISCALIZACIÓN Y RESPONSABILIDAD}

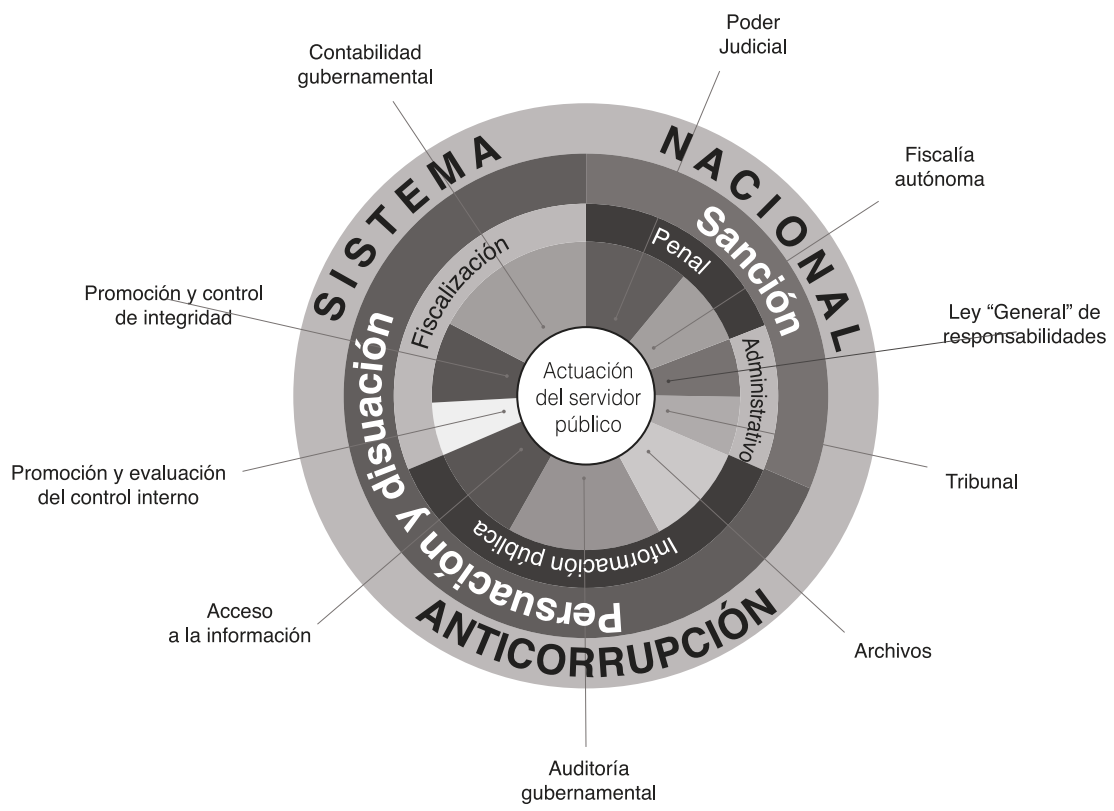

FUENTE: ASF, Informe General de la Cuenta Pública, 2013.

El último de los subsistemas que - bajo nuestra propuesta - podría integrar un Sistema Nacional de Rendición de Cuentas es el de Participación y Contraloría Social, el cual — según pensamos — involucra la participación ordenada y coherente de la ciudadanía mexicana en las tareas de observación, vigilancia, solicitud de información, análisis de hechos y denuncia de actos irregulares o ilegales.

Respecto a la participación ciudadana en el ámbito de acción del gobierno, el doctor Mauricio Merino nos dice que constituye un componente 
Esta revista forma parte del acervo de la Biblioteca Jurídica Virtual del Instituto de Investigaciones Jurídicas de la UNAM

connatural a la rendición de cuentas, de ahí su importancia en el contexto del vigente SNA. ${ }^{36}$

A pesar de que la Ley General de Desarrollo Social nos habla de la obligación de los tres niveles de gobierno por garantizar el derecho social a participar de manera activa y corresponsable en la planeación, ejecución, evaluación y supervisión de la política social (artículos 61 a 66), podemos sostener que hasta hoy el tratamiento de la participación social ha sido, en muchos casos, laxo, opcional en cuanto a su atención e incluso sólo discursivo. ${ }^{37}$

Por esa razón, la actual inclusión de un Comité de Participación Ciudadana previsto en el marco constitucional del SNA es una buena y alentadora noticia para fortalecer la rendición de cuentas de cara a la sociedad. Dicho Comité, compuesto por cinco expertos en transparencia, rendición de cuentas o combate a la corrupción, representa el inicio de un ciclo importante mediante el cual se puede llegar a establecer un diálogo entre las instituciones y la sociedad, una verdadera democracia participativa en la que se escuchen las iniciativas, propuestas, sugerencias y recomendaciones de la sociedad organizada.

Tratándose de la Contraloría Social legalmente es definida como el mecanismo de los beneficiarios de los programas de desarrollo social, por el que, de manera organizada, pueden verificar el cumplimiento de las metas y la correcta aplicación de los recursos públicos asignados a dichos programas. Las funciones de la Contraloría Social son: ${ }^{38}$

1. Solicitar información a las autoridades federales, estatales y municipales responsables de los programas de desarrollo social que se consideren necesarias para el desempeño de sus funciones.

2. Vigilar el ejercicio de los recursos públicos y la aplicación de los programas de desarrollo social conforme a la ley y a las reglas de operación.

3. Emitir informes sobre el desempeño de los programas y ejecución de los recursos públicos.

36 Merino, Mauricio, Veloz Márquez, Liliana y Hernández Colorado, Jaime, op. cit., p. 98 .

37 Auditoría Superior de la Federación, Informe General de la Cuenta Pública 2013, op. cit., p. 67.

38 Artículos 69 a 71 de la Ley General de Desarrollo Social. 
Esta revista forma parte del acervo de la Biblioteca Jurídica Virtual del Instituto de Investigaciones Jurídicas de la UNAM

4. Atender e investigar las quejas y denuncias presentadas sobre la aplicación y ejecución de los programas.

5. Presentar ante la autoridad competente las quejas y denuncias que puedan dar lugar al fincamiento de responsabilidades administrativas, civiles o penales relacionadas con los programas sociales.

Como podemos ver, la participación y contraloría social se valen de los mecanismos de transparencia, vigilancia y responsabilidades para velar por el óptimo funcionamiento de las instituciones y la sanción de los actos ilegales.

En el caso del rol de la ASF con la participación y contraloría social existen muestras de las actividades que ha venido efectuando, por poner sólo tres ejemplos: a) el anteriormente citado Sistema Público de Consulta de Auditorías, visible en la página web de la ASF; b) la guía para el ciudadano que explica con claridad a la sociedad ¿qué es? y ¿qué hace la ASF?, y c) la línea ética de denuncia (vía telefónica y virtual) para hacer del conocimiento de la ASF las irregularidades en la utilización de los recursos públicos federales.

Por si esto fuera poco, en su trabajo de fiscalización superior la ASF ha diferenciado este tema en dos ámbitos distintos para su análisis: los programas federales y el gasto federalizado.

En el primer caso, la ASF ha llegado a la conclusión de que la participación social hasta ahora tiene un impacto limitado en la vigilancia de los programas sociales, con porcentajes de cobertura de contraloría social muy bajos. $^{39}$

En el segundo caso, la ASF ha impulsado una estrategia para conformar una red de auditoría social que coadyuve a la fiscalización del gasto federalizado, principalmente en las áreas de educación, salud, infraestructura de servicios básicos y seguridad pública, identificando que hay "resistencias que se respaldan en argumentos como la falta de preparación académica de la población participante, peligro de politización del trabajo de las organizaciones, resistencias sindicales y la falta de presupuesto para capacitación de las figuras participativas". ${ }^{40}$

39 Por ejemplo, el programa Pensión para Adultos Mayores cuenta con un universo de 84, 648 localidades y la cobertura social es de 1,020 localidades con contraloría, es decir, un porcentaje de sólo el 1.2\%. Auditoría Superior de la Federación, Informe General de la Cuenta Pública 2013, op. cit., p. 68.

40 Ibidem, p. 69. 
Esta revista forma parte del acervo de la Biblioteca Jurídica Virtual del Instituto de Investigaciones Jurídicas de la UNAM www.juridicas.unam. $m x$

Como corolario de estas reflexiones, nos parece claro que la ASF, a través del trabajo que ha desarrollado tanto en el ámbito de la exigencia de las responsabilidades públicas como en el rubro de la promoción de la participación y contraloría social, está llamada a fomentar — en conjunto con el Comité de Participación Ciudadana del SNA - la construcción y diseño del Subsistema de Responsabilidades y del Subsistema de Participación y Contraloría Social.

Los desafíos que en ese tenor habrá de superar la ASF no son menores, pues ambos subsistemas presentan problemáticas particulares que afectan su funcionamiento idóneo.

En el caso del Subsistema de Responsabilidades, en estudios previos se ha visto que es el más descuidado de los subsistemas, tal como lo evidencian los pocos avances en la materia y el hecho de que las modalidades de responsabilidad se fundamenten en criterios políticos, en normas que permiten amplios márgenes de discrecionalidad (y corrupción), en órganos de control que no gozan de plena autonomía para sancionar a los servidores públicos, en sanciones o penas ineficaces y en un sistema de responsabilidad patrimonial $\sin$ garantías. ${ }^{41}$

Pero también el Subsistema de Participación y Contraloría Social tiene aspectos susceptibles de mejora, como la misma ASF ha identificado y precisado puntualmente, sólo por mencionar un ejemplo: la imprescindible necesidad de establecer ordenamientos obligatorios para que los ejecutores de los programas sean responsables de proporcionar información y ofrecer canales de expresión y respuesta a los cuestionamientos, quejas y denuncias de las representaciones ciudadanas. ${ }^{42}$

En consecuencia, para la conformación de un Sistema Nacional de Rendición de Cuentas, la ASF habrá de emprender el estudio y análisis de las problemáticas propias de todos los subsistemas, contribuyendo a su debate mediante información y promoción de su integración y funcionamiento armónico.

Para lograr lo anterior, una estrategia destacada será - como veremos en el apartado siguiente - apreciar lo que en otras latitudes se ha hecho para la integración del papel de las entidades fiscalizadoras y aquellas entidades o instituciones que participan en la exigencia de rendición de cuentas y el combate a la corrupción.

\footnotetext{
41 Gutiérrez Salazar, Miguel Ángel, op. cit., p. 95.

42 Auditoría Superior de la Federación, Informe general de la cuenta pública 2013, op. cit., p. 69.
} 
Esta revista forma parte del acervo de la Biblioteca Jurídica Virtual del Instituto de Investigaciones Jurídicas de la UNAM

\section{El modelo alemán de fiscalización superior y su vinculación con las instituciones de rendición de cuentas y el combate a la corrupción}

Los estudios comparados en materia de fiscalización superior pueden resultar útiles y benéficos para allegarse de información relevante que permita conocer las buenas prácticas y el grado de avance (o retroceso) que determinadas entidades de fiscalización presentan para el ejercicio de sus funciones; asimismo, de acuerdo con el punto de vista del auditor superior de la Federación, conocer los modelos de fiscalización permite aprender las metodologías, enfoques y logros que puedan emplearse en nuestro país. ${ }^{43}$

Estudios como éstos se han realizado con antelación y han demostrado que el conocimiento de las prácticas internacionales sirve de impulso para mejorar los sistemas propios de cada país. ${ }^{44}$

No obstante, no debemos olvidar que no existen modelos de fiscalización perfectos, por lo que la información y los alcances del modelo que expondremos deberán valorarse de acuerdo al estado de la materia y al contexto general de fiscalización que hoy tenemos en México.

En este caso, nos proponemos revisar la entidad de fiscalización alemana, ${ }^{45}$ la cual — de acuerdo al análisis que hemos efectuado- representa un modelo internacional exitoso por su grado de independencia, por su eficacia y por la vinculación integral que guarda con el resto de las instituciones que tienen como misión la rendición de cuentas y el combate a la corrupción:

\footnotetext{
43 Auditoría Superior de la Federación, Pesos y contrapesos, México, Auditoría Superior de la Federación, Canal del Congreso, 2011, p. 14.

44 Figueroa Neri, Aimée, La Auditoría Superior de México en el horizonte internacional de la fiscalización superior, México, Auditoría Superior de la Federación, 2007.

45 A manera de antecedentes, debemos señalar que en México estuvo vigente el modelo de "tribunal de cuentas" en el siglo XIX, en términos de la Ley del 14 de marzo de 1838, emitida durante la Presidencia de Anastasio Bustamante; además, existió el proyecto de Teodosio Lares de 1853, durante el periodo de Antonio López de Santa Anna en la Presidencia y durante el Segundo Imperio en 1865. Recientemente (2015), por parte del senador Miguel Barbosa, existió una propuesta para que la Auditoría Superior de la Federación se convierta en un Tribunal de Cuentas, disponible en: http:// prd.senado.gob. $m x / w p / ? p=58333$ (última fecha de consulta: 29 de marzo de 2017).
} 
Esta revista forma parte del acervo de la Biblioteca Jurídica Virtual del Instituto de Investigaciones Jurídicas de la UNAM www.juridicas.unam.mx https://biblio.juridicas.unam.mx/bjv

https://revistas.juridicas.unam.mx

DOI: http://dx.doi.org/10.22201/iij.24484881e.2017.37.11453

\section{A. El Tribunal Federal de Cuentas Alemán}

La entidad fiscalizadora alemana es el Tribunal Federal de Cuentas (en adelante TFC), ${ }^{46}$ creado en 1950 pero fortalecido en 1998 a efecto de ejercer una fiscalización con plena autonomía e independencia de los poderes políticos y con criterios de alta especialización para buscar la consistencia, eficiencia y eficacia de la administración pública federal. ${ }^{47}$

El TFC cuenta con el apoyo de nueve oficinas de auditoría, las cuales reemplazaron a las anteriores oficinas de preauditorías (o de intervención), que orgánicamente formaban parte de los ministerios federales y demás organismos de la administración pública federal. Las nueve oficinas de auditoría integran a un total de cincuenta divisiones de fiscalización. El TFC emplea a seiscientas personas entre auditores y personal de apoyo; su personal está altamente especializado y como norma es apartidista e imparcial. ${ }^{48}$

Entre sus actividades se encuentra examinar las finanzas públicas, los fondos de la Federación, las empresas federales, las entidades gestoras de la seguridad social y la actividad de la Federación en empresas privadas con las que tenga participación; al mismo tiempo, revisa que las actividades de estos entes se realicen bajo los lineamientos de las leyes federales. ${ }^{49}$

El TFC debe informar anual y directamente al gobierno, Parlamento y Senado. Sus facultades se regulan por ley. Con base en esto, tiene una existencia garantizada; su naturaleza es la de un órgano fiscalizador independiente, sujeto a la ley de manera exclusiva y que se ubica entre los poderes Ejecutivo y Legislativo como un órgano de apoyo. Entre los informes y productos relevantes que genera se encuentran: ${ }^{50}$

a) Informe anual. Contiene observaciones de la cuenta pública anual; resultados de las auditorías relevantes con propuestas concretas de aplicación de medidas y acciones; casos importantes en los que

46 Página web del Tribunal Federal de Cuentas Alemán: www.bundesrechnungshof.de (última fecha de consulta: 29 de marzo de 2017).

47 Unidad de Evaluación y Control, Comisión de Vigilancia de la Auditoría Superior de la Federación, Fiscalización Superior Comparada. Una aproximación al estudio de los modelos de fiscalización superior en el mundo, México, LIX Legislatura, Cámara de Diputados, 2005, p. 112.

Idem.

Idem.

50 Figueroa Neri, Aimée, op. cit., p. 58. 
Esta revista forma parte del acervo de la Biblioteca Jurídica Virtual del Instituto de Investigaciones Jurídicas de la UNAM

la administración pública siguió las recomendaciones del TFC, etcétera.

b) Informe bianual de seguimiento a las medidas tomadas por el gobierno, el Poder Legislativo y las entidades fiscalizadas, que se basa en el informe anual respectivo.

c) Informes especiales que se elaboran cuando se requiere una información inmediata para el Parlamento o el gobierno.

d) Informes particulares, en los casos de organismos o instituciones en las cuales no corresponde al Parlamento la aprobación de la gestión gubernamental (descargo); se prevé en la ley la elaboración de informes anuales por parte del TFC para las entidades o consejos responsables de tal descargo (por ejemplo, Banco Federal Alemán).

e) Dictámenes del delegado federal para la buena gestión pública.

f) Informe de impacto, dirigido al público.

g) Opiniones particulares para el gobierno federal y sus ministerios.

Es tal la importancia de los informes del TFC, que incluso el presidente alemán ha tenido que comparecer ante el Parlamento y la prensa para explicar asuntos detectados como la alta deuda pública, la ineficacia de los mecanismos de control interno de las estructuras de gobierno y la disparidad entre metas y resultados de los programas públicos, entre otros. ${ }^{51}$

En suma, como podemos apreciar, es interesante y destacada la labor fiscalizadora del TFC. Además, un aspecto digno de resaltar lo constituye la relación institucional que ha establecido para coordinarse de forma puntual con otras instituciones del Estado alemán para el combate a la corrupción.

Sobre este tema, y en opinión de Uwe Schreiner, director de Auditoría del TFC, la corrupción y el lavado de dinero son amenazas para las instituciones políticas, los países y las economías; debido a estos actos nocivos cometidos por individuos o empresas, en todo el mundo se pierden miles de millones de euros o dólares cada año. Por esa razón, desde hace aproximadamente diez años el TFC viene colaborando en un grupo de trabajo específico de la Organización Internacional de Entidades Fiscalizadoras Superiores (INTOSAI), para discutir ideas relacionadas con

51 Unidad de Evaluación y Control, Comisión de Vigilancia de la Auditoría Superior de la Federación, op. cit., p. 115. 
Esta revista forma parte del acervo de la Biblioteca Jurídica Virtual del Instituto de Investigaciones Jurídicas de la UNAM

los mecanismos de combate a la corrupción y lavado de dinero en áreas específicas, gobiernos, países, etcétera. La variedad de culturas de auditoría internacional que se expone en ese grupo de trabajo permite generar nuevas ideas para que los auditores del TFC tengan un mejor entendimiento y se posicionen de manera idónea para realizar un trabajo profesional en contra de estos actos dañinos. ${ }^{52}$

De igual manera, Schreiner señala que en el combate a la corrupción tienen limitaciones (pues no son fiscales o policías), pero en su papel de auditores de las organizaciones estatales sí pueden revisar si han establecido una estructura para combatir el lavado de dinero o para prevenir la corrupción, si han establecido un sistema de protección para denunciantes, estrategias de comunicación, o análisis de riesgos para identificar las áreas más sensibles a la corrupción en cada organización, haciendo las sugerencias para mejorar las estructuras que se tienen o incluso para implementarlas cuando no existan..$^{53}$

En los casos en que el TFC detecta un delito, procede a informar a la policía y a la Fiscalía, y se hacen los seguimientos correspondientes. Asimismo, el TFC establece vínculos importantes con el Ministerio del Interior, el cual se encarga de establecer normas y bases que deberán ser empleadas por todas las instituciones gubernamentales, por los ministerios y por las autoridades alemanas. La cooperación con el Ministerio del Interior comprende el intercambio de información sobre los resultados de las auditorías, para procurar la mejora de los aspectos normativos. ${ }^{54}$

A nuestro parecer, el buen desempeño del TFC en los rubros de fiscalización y coordinación en el combate a la corrupción es uno de los elementos que ubican a Alemania en el lugar diez de los 176 países encuestados dentro del Índice de Percepción de la Corrupción (IPC)-2016 de Transparencia Internacional, como ilustra la gráfica siguiente:

52 Entrevista con Uwe Schreiner, director de la Auditoría del TFC, parte de la emisión del Programa Pesos y Contrapesos de la Auditoría Superior de la Federación del 3 de agosto de 2015, disponible en: https://www.youtube.com/watch? $v=11$ c4s Y2HFOk (última fecha de consulta: 29 de marzo de 2017). 
Esta revista forma parte del acervo de la Biblioteca Jurídica Virtual del Instituto de Investigaciones Jurídicas de la UNAM www.juridicas.unam.mx https://biblio.juridicas.unam.mx/bjv https://revistas.juridicas.unam.mx

DOI: http://dx.doi.org/10.22201/iij.24484881e.2017.37.11453

LA AUDITORÍA SUPERIOR DE LA FEDERACIÓN...

ÍNDICE DE PERCEPCIONES DE LA CORRUPCIÓN 2016 DE LA TRANSPARENCIA INTERNACIONAL

\begin{tabular}{|c|c|c|c|c|c|c|c|}
\hline \multicolumn{5}{|c|}{ CORRUPTION PERCEPTIONS INDEX 2016} & \multirow[b]{2}{*}{$\begin{array}{l}2013 \\
\text { Score }\end{array}$} & \multirow[b]{2}{*}{\begin{tabular}{|l|}
2012 \\
Score
\end{tabular}} & \multirow[b]{2}{*}{ Region } \\
\hline $\begin{array}{l}2016 \\
\text { Rank }\end{array}$ & Country & $\begin{array}{l}2016 \\
\text { Score }\end{array}$ & $\begin{array}{l}2015 \\
\text { Score }\end{array}$ & $\begin{array}{l}2014 \\
\text { Score }\end{array}$ & & & \\
\hline 1 & Denmark & 90 & 91 & 92 & 91 & 90 & Europe and Central Asia \\
\hline 1 & New Zeland & 90 & 88 & 91 & 91 & 90 & Asia Pacific \\
\hline 3 & Finland & 89 & 90 & 89 & 89 & 90 & Europe and Central Asia \\
\hline 4 & Sweden & 87 & 89 & 87 & 89 & 88 & Europe and Central Asia \\
\hline 5 & Switzerland & 86 & 86 & 86 & 85 & 86 & Europe and Central Asia \\
\hline 6 & Norway & 85 & 87 & 86 & 86 & 85 & Europe and Central Asia \\
\hline 7 & Singapore & 84 & 85 & 84 & 86 & 87 & Asia Pacific \\
\hline 8 & Netherlands & 83 & 87 & 83 & 83 & 84 & Europe and Central Asia \\
\hline 9 & Canada & 82 & 83 & 81 & 81 & 84 & Americas \\
\hline 10 & Germany & 81 & 81 & 79 & 78 & 79 & Europe and Central Asia \\
\hline
\end{tabular}

FUENTE: Transparencia Internacional. Índice de Percepciones de la Corrupción (IPC) 2016.

Conforme a lo expuesto por Figueroa Neri, hay tres condiciones del TFC que hacen que no sea visto como la tradicional entidad de fiscalización superior en su papel de "vigilante" del Ejecutivo: 55

1. La autonomía absoluta que goza al no estar supeditado ni formar parte de alguno de los poderes públicos, sino sólo al imperio de la ley.

2. La intervención de ambas cámaras del Parlamento en el proceso de descargo o aprobación de la gestión financiera del Ejecutivo que se hace por medio de la revisión del TFC de la cuenta pública anual, lo que refleja un sistema de frenos y contrapesos más activo y continuo.

3. El blindaje político que se da a los titulares del TFC, a través de su independencia judicial, material y personal, y que sea sólo la Corte Federal de Justicia la que pueda resolver sobre su remoción o sanciones.

Bajo esas características, el TFC pasa de ser una entidad de fiscalización superior como normalmente se conocen, a una agencia especializada que

55 Figueroa Neri, Aimée, op. cit., p. 66. 
Esta revista forma parte del acervo de la Biblioteca Jurídica Virtual del Instituto de Investigaciones Jurídicas de la UNAM

realiza auditoría gubernamental con impacto en todo el ciclo financiero y apoya así la fiscalización superior que corresponde al Parlamento y también al gobierno mismo para un mejor desempeño de su gestión financiera. ${ }^{56}$

A nuestra manera de ver las cosas, para el caso mexicano será importante aprender de las experiencias internacionales como el modelo de fiscalización alemán.

El grado de independencia del TFC y su vinculación con los órganos que combaten la corrupción pueden ser ejemplo a seguir por parte de la ASF, a efecto de instaurar un régimen de integridad, fiscalización y combate a la corrupción de mayor calidad, sin dejar de atender — desde luego — las circunstancias y el contexto que hoy predomina en nuestro país, en el marco del vigente SNA.

\section{REFLEXIONES FINALES}

Para finalizar el presente trabajo, queremos formular algunas ideas y propuestas que surgieron del análisis que realizamos y que nos parecen relevantes para coadyuvar al mejor desempeño de la ASF en su papel de órgano fiscalizador y actor importante en el combate a la corrupción en México:

1. Consideramos que son al menos tres grandes retos los que afronta la ASF en el contexto del SNA: la elaboración de políticas de fiscalización claras, homogéneas y congruentes; propiciar una interacción y coordinación efectiva entre los integrantes del SNA; y cumplir con las nuevas facultades constitucionales de revisión y fiscalización.

Para superar exitosamente los retos anteriores, la ASF deberá aprovechar la experiencia acumulada a lo largo de los años, especialmente tras los avances que se tienen en el ámbito del Sistema Nacional de Fiscalización, en los que ya se han alcanzado criterios conjuntos y parámetros de fiscalización que puede servir de modelo para el diseño de políticas anticorrupción coherentes.

Asimismo, la interacción que se ha generado en el ámbito del Sistema Nacional de Fiscalización es una plataforma importante que

56 Idem. 
Esta revista forma parte del acervo de la Biblioteca Jurídica Virtual del Instituto de Investigaciones Jurídicas de la UNAM

debe tomarse de base para iniciar el diálogo fluido y constante entre la ASF y las instituciones que conforman el SNA.

Para cumplir satisfactoriamente con sus nuevas facultades constitucionales, la ASF debe contar con los recursos humanos, materiales y técnicos indispensables, pero sobre todo debe aspirar a una independencia real, alejada de influencias políticas externas que puedan mermar o hacer ineficaz su trabajo.

2. Pensamos que el SNA tiene propósitos benéficos para el combate a la corrupción en México, no obstante, según nuestro análisis es indispensable que trascienda los temas de acceso a la información y fiscalización, fortaleciendo los rubros de la responsabilidad de los servidores públicos, y participación y contraloría social.

Por ello, proponemos la construcción de un Sistema Nacional de Rendición de Cuentas compuesto por una serie de elementos normativos (leyes, lineamientos, circulares), organizacionales, de políticas (anticorrupción, de participación social, etcétera), criterios, procesos y acciones destinadas al buen funcionamiento de nuestras instituciones y a la desincentivación y castigo de los actos corruptos en México.

Nos parece que para alcanzar un Sistema Nacional de Rendición de Cuentas eficaz, se requerirá del conocimiento de los subsistemas que lo integran (acceso a la información, fiscalización, responsabilidades y participación y contraloría social). Es aquí donde la ASF tiene una oportunidad histórica de promover un régimen de integridad mediante la visión de sistema que agrupe los esfuerzos de múltiples instituciones y actores sociales en pro de un régimen de gobierno honesto y eficaz.

3. Estudiar los modelos internacionales de fiscalización es una metodología útil para allegarse de información valiosa que pueda contribuir a la mejora de la ASF. En este caso, el modelo alemán de fiscalización es muestra de una institución independiente que no sólo efectúa su labor de vigilancia, sino que además actúa en coordinación cercana con otras entidades para el combate a la corrupción. Sin duda aprender de las características y logros del TFC puede servir de orientación para el fortalecimiento de la ASF, desde luego, guardando las proporciones y el contexto del modelo mexicano de fiscalización. 
Esta revista forma parte del acervo de la Biblioteca Jurídica Virtual del Instituto de Investigaciones Jurídicas de la UNAM

En ese orden de ideas, nos parece indispensable que la ASF continúe participando en el grupo internacional de Entidades de Fiscalización Superior que integran la INTOSAI, ya que de esa interacción se aprenderán culturas, modelos y buenas prácticas de fiscalización que pueden llegar a optimizar el trabajo nacional que efectúa la ASF.

4. Es común escuchar que el papel de la ASF debe ser eminentemente preventivo, sin embargo, conforme a la reforma constitucional anticorrupción 2015, según la cual la ASF puede investigar hechos de corrupción, es que debe irse superando ese criterio, en virtud de que los altos índices de corrupción en nuestro país lo exigen y las Entidades de Fiscalización Superior en el mundo - como el modelo de fiscalización alemán que estudiamos - vienen incorporando las indagaciones de actos de corrupción como una de sus tareas esenciales, las cuales en muchos casos derivan en la promoción de responsabilidades administrativas y en denuncias penales. ${ }^{57}$

Consideramos que como institución de rendición de cuentas y combate a la corrupción, la ASF debe ir más allá de las auditorías formales y de las actividades de evaluación y asesoramiento para emprender un papel más activo y profesional en sus investigaciones y denuncias de actos por corrupción.

En este sentido, su vinculación con el régimen de responsabilidades y con la contraloría ciudadana resultará importante para permitir que los resultados de la fiscalización de los recursos públicos ya no sólo sirvan para orientar a las instituciones en el uso adecuado de los mismos, sino para que, en los hechos, se sancione a quienes abusen del poder y de los recursos públicos.

57 En este sentido, compartimos la opinión de Buchahin Abulhosn, quien estima que una de las obligaciones prioritarias en la práctica auditora en el sector público es buscar el juicio de responsabilidad que deriva de la ejecución de conductas que integran delitos cometidos en contra de la administración pública. Como ella sostiene, encarar su estudio durante la investigación en la actividad fiscalizadora redunda en la mejora de las buenas prácticas realizadas durante el procedimiento de investigación. Buchahin Abulhosn, Muna Dora, "Apuntes sobre la auditoría forense en el sector público y en el sector privado", Fraude, Revista Especializada de ACFE, México, núm. 5, enero-febrero de 2014, disponible en: http://www.revistadelfraude.com/enero_febrero_14/angulos.html (última fecha de consulta: 29 de marzo de 2017). 
Esta revista forma parte del acervo de la Biblioteca Jurídica Virtual del Instituto de Investigaciones Jurídicas de la UNAM www.juridicas.unam.mx https://biblio.juridicas.unam.mx/bjv https://revistas.juridicas.unam.mx

DOI: http://dx.doi.org/10.22201/iij.24484881e.2017.37.11453

LA AUDITORÍA SUPERIOR DE LA FEDERACIÓN...

\section{BIBLIOGRAFÍA}

ACKerman, John M. y Astudillo, César (coords.), La autonomía constitucional de la Auditoría Superior de la Federación, UNAM, Instituto de Investigaciones Jurídicas, México, 2009.

Aguilar Villanueva, Luis, El estudio de las políticas públicas, 3a. ed., México, Miguel Ángel Porrúa, 2007.

Artículo periodístico intitulado: "14 Claves del Sistema Nacional Anticorrupción", disponible en: http://www.cnnexpansion.com/economia/ 2015/02/26/12-claves-del-sistema-nacional-anticorrupcion.

ANDRADE MARTíNEZ, Víctor Manuel, Evolución del marco jurídico de la Fiscalización Superior en México, México, Auditoría Superior de la Federación.

Auditoría SuPERIOR DE LA FEDERACIÓN, Informe general de la cuenta pública 2013, México, Auditoría Superior de la Federación, México, 2015, disponible en: http://www.asf.gob.mx/uploads/55_Informes_de auditoria/Informe_General_CP_2013.pdf.

, Pesos y contrapesos, México, Auditoría Superior de la Federación, Canal del Congreso, 2011.

, 180 años de rendición de cuentas y fiscalización en México, eventos conmemorativos-memoria, México, Cámara de Diputados, Auditoría Superior de la Federación, 2004.

Bohórquez, Eduardo, Conflicto de interés y Sistema Nacional Anticorrupción, disponible en: http://www.eluniversalmas.com.mx/editoriales /2015/02/74665.php

Buchahin ABulhosn, Muna Dora, "Apuntes sobre la auditoría forense en el sector público y en el sector privado, fraude", Revista Especializada de ACFE, México, núm. 5, enero-febrero de 2014, disponible en: http://www.revistadelfraude.com/enero_febrero_14/angulos.html.

CASAR, María Amparo, Anatomía de la corrupción, México, IMCO, CIDE, 2015.

Cejudo RAMíRez, Guillermo Miguel, Todas las piezas en su lugar: la arquitectura institucional de la rendición de cuentas en México, México, Auditoría Superior de la Federación, 2005.

Figueroa Neri, Aimée, La Auditoría Superior de México en el horizonte internacional de la fiscalización superior, México, Auditoría Superior de la Federación, 2007. 
Esta revista forma parte del acervo de la Biblioteca Jurídica Virtual del Instituto de Investigaciones Jurídicas de la UNAM www.juridicas.unam.mx https://biblio.juridicas.unam.mx/bjv

https://revistas.juridicas.unam.mx

DOI: http://dx.doi.org/10.22201/ijj.24484881e.2017.37.11453

GonzÁlez LlaCA, Edmindo, Corrupción, patología colectiva, México, INAP, 2005, disponible en: http://biblio.juridicas.unam.mx/libros/libro.htm? $l=1680$.

GutiÉRrez SAlazAr, Miguel Ángel, Hacia la construcción de un sistema de rendición de cuentas armónico, como mecanismo para el fortalecimiento de la eficacia institucional y el combate a la corrupción en México, México, Auditoría Superior de la Federación, Cámara de Diputados, CIDE-UNAM-ASOFIS, 2013.

KAISER, Max, El combate a la corrupción. La gran tarea pendiente en México, México, ITAM-Miguel Ángel Porrúa, 2014.

MALEM SEÑA, Jorge, F., "La corrupción política", Jurídica, Anuario del Departamento de Derecho de la Universidad Iberoamericana, México, núm. 341, 2001.

Merino, Mauricio, Politicas públicas. Ensayo sobre la intervención del Estado en la solución de problemas públicos, México, CIDE, 2013.

, Informe sobre la evolución y el desempeño de la Auditoría Superior de la Federación, México, Cámara de Diputados, CIDE, 2009.

, LÓPEZ AYllón, Sergio y CEJUdo, Guillermo (coords.), La estructura de la rendición de cuentas en México, México, UNAM, Instituto de Investigaciones Jurídicas, CIDE, 2010.

PORTAL, Juan Manuel, "Relanzamiento del SNF", blog de la ASF, disponible en: http://blog-asf.gob. $m x / ? p=886$.

, "Mensaje del auditor superior de la Federación con motivo del relanzamiento del Sistema Nacional de Fiscalización", disponible en: http://www.asf.gob.mx/uploads/74_Mensajes_del_Titular/Relanzamiento_del_Sstema_Nacional_de_Fiscalizacion_22_Jul.pdf.

—_ "Cambiemos y mejoremos todos, red por la rendición de cuentas", disponible en: http://rendiciondecuentas.org.mx/cambiemos-y-me joremos-todos/.

PESCHARD, Jacqueline (coord.), Hacia el Sistema Nacional de Transparencia, México, UNAM, Instituto de Investigaciones Jurídicas, Seminario Universitario de Transparencia, 2016.

Puente DE la Mora, Ximena, Sistema Nacional de Transparencia, base de un México más abierto, disponible en: http://mexico.cnn.com/opinion/2015/06/23/opinionsistemanacionaldetranspareca-base-de-unmexico-mas-abierto 
Esta revista forma parte del acervo de la Biblioteca Jurídica Virtual del Instituto de Investigaciones Jurídicas de la UNAM www.juridicas.unam.mx https://biblio.juridicas.unam.mx/bjv https://revistas.juridicas.unam.mx

DOI: http://dx.doi.org/10.22201/iij.24484881e.2017.37.11453

ROMERO GUDIÑO, Alejandro, Génesis, evolución y retos de la fiscalización superior en México, México, Cámara de Diputados, LXIII Legislatura, Centro de Estudios de Derecho e Investigaciones Parlamentarias, 2016. SCHEDLER, Andreas, "Conceptualizing accountability", en SCHEDLER, Andreas et al. (eds.), The Selfrestraning State: Power and Accountability in New Democracies, Boulder, Lynne Rienner, 1999.

¿Qué es la rendición de cuentas?, 4a. ed., México, IFAI, Cuadernos de transparencia, núm. 3, 2007.

Unidad de Evaluación y Control, Comisión de Vigilancia de la Auditoría Superior de la Federación, Fiscalización superior comparada. Una aproximación al estudio de los modelos de fiscalización superior en el mundo, México, LIX Legislatura, Cámara de Diputados, 2005.

Sitios web

Auditoría Superior de la Federación, disponible en: http://www.asf.gob. $m x /$.

Consejo de la Judicatura Federal, disponible en: http://www.cjf.gob.mx/ mision.htm.

Instituto Nacional de Acceso a la Información y Protección de Datos Personales, disponible en: http://inicio.inai.org.mx/SitePages/misionVio sionObjetivos.aspx.

Sistema Nacional de Fiscalización, disponible en: http://www.snf.org.mx/ definici $\%$ C 3\%B3n.aspx.

Sistema Nacional de Transparencia, disponible en: http://www.snt.org.mx/

Sistema Público de Consulta de Auditorías, ASF, disponible en: http:// www.asfdatos.gob.mx/.

Tribunal Federal de Cuentas Alemán, disponible en: www.bundesrech nungshof.de.

Real Academia Española, disponible en: http://www.rae.es/.

Fecha de recepción: 11 de enero de 2016.

Fecha de dictamen: 25 de marzo de 2017. 